\title{
Adverse Selection and Entrepreneurship in a Model of Development*
}

\author{
Esteban Jaimovich \\ Collegio Carlo Alberto, Turin, (TO) 10024, Italy \\ esteban.jaimovich@carloalberto.org
}

September 2009

\begin{abstract}
This paper presents a theory in which talented entrepreneurs are identified as the key agents driving the process of development and modernisation. Entrepreneurial skills are private information, which prevents full risk sharing. Development into a modern industrial economy might fail to take place, since potentially talented entrepreneurs may refrain from taking on the entrepreneurial risks as a way to avoid income shocks. An interesting feature of the model is the fact that the informational asymmetries are endogenous to the process of development, as they are related to the heterogeneity in entrepreneurial skills required in the manufacturing activities.
\end{abstract}

Keywords: Adverse selection; risk-sharing; poverty traps JEL classification: O12; O16; D81; D82.

\footnotetext{
${ }^{*}$ I am grateful to Maristella Botticini, Maitreesh Ghatak, Vincenzo Merella, Andrew Newman, Nicola Pavoni, Fabrizio Zilibotti, and two anonymous referees for helpful comments.
} 


\section{Introduction}

Dealing with large swings in consumption is a central concern for all societies. Under complete markets, individuals are able to diversify away all their idiosyncratic risks. However, when markets are incomplete and full risk sharing cannot be achieved, agents may seek to prevent consumption shocks by avoiding certain activities that entail substantial risk, even if those activities should be carried out in a first-best environment. This paper claims that this phenomenon becomes especially critical in relatively poor economies that intend to start the process of development and industrialisation. The argument rests on two main ideas. The first is that the behaviour of the poor is highly sensitive to the presence of income risks. The second is the notion that informational asymmetries related to intrinsic skills are more prevalent in the urban industrial economy than in the traditional village economy.

The importance of risk aversion in poor societies is confirmed by the evidence in Townsend (1994) and Udry (1994). More significantly, these articles show that a substantial amount of consumption smoothing is achieved within village economies. However, the empirical development literature also stresses the fact that risk sharing in poor economies is not usually accomplished via impersonal market exchanges, as modelled by standard economic theory, but tends to be the result of more informal arrangements between village members - see Besley (1995) for a survey of this literature.

One key aspect in which village economies differ from modern industrial ones is in the amount of information required for their efficient operation and how well this information flows. Within the village, information about peers and their behaviour appears to be relatively unpolluted. This is confirmed, for example, by the success of group lending programmes such as the Grameen Bank [Stiglitz (1990)]. ${ }^{1}$ In contrast, in the industrial economy anonymous markets and informational asymmetries are commonplace. Furthermore, the relative complexity of entrepreneurial manufacturing activities, compared to traditional agricultural tasks, means that the selection of the correct individuals to whom finance should be granted becomes a fundamental issue to deal with during the process of industrialisation.

\footnotetext{
${ }^{1}$ See also the direct field evidence for rural villages in northern Nigeria in Udry (1990), where it is argued that informational asymmetries within those villages are unimportant.
} 
This paper presents a model in which risk-averse individuals are heterogeneous in terms of their entrepreneurial skills. In particular, only some individuals in the economy possess the required skills to become entrepreneurs in the manufacturing sector. Furthermore, those skills are private information, which generates an adverse selection problem in the financial markets and precludes full insurance against idiosyncratic entrepreneurial risks. In this context, potentially talented entrepreneurs might decide to refrain from investing in entrepreneurial projects (even if those projects yield high expected returns), choosing instead to remain attached to the traditional sector where informational asymmetries are not such a serious impediment to risk sharing. Lack of entrepreneurship retards the development and modernisation of the economy and, in some cases, it may even lead to development traps.

The model features an overlapping-generations economy where agents live for two periods. The old generation may undertake entrepreneurial projects that are subject to idiosyncratic risks. The probability of success in these projects is related to the entrepreneurial skills. The young generation supplies labour, which is used as an input by the entrepreneurs. Since wages are fixed, all the (uninsured) risks must be borne by the entrepreneurs. Private information prevents full risk pooling, and therefore affects the amount of entrepreneurial investment by the old, which in turn leads to lower labour demand and lower wages for the young. An important assumption in the model is the fact that individuals display constant relative risk aversion (CRRA). As a result, the poorer they are, the more strongly risktaking is deterred by the presence of uninsured risk. ${ }^{2}$ In the model, this implies that if the old generation is poor, entrepreneurial investment will be low, and so will labour demand and wages as a consequence. This feedback between investment and wages means that the incomes of different generations will display persistence. Furthermore, when entrepreneurial projects are sufficiently risky, this feedback may become so strong that it may lead to the appearance of poverty traps and multiple long-run equilibria.

Regarding the CRRA assumption (and, more generally, that absolute risk aversion decreases with income), this essentially captures the notion that the poor are particularly

\footnotetext{
${ }^{2}$ This is actually a property of preferences with decreasing absolute risk aversion (DARA). Since CRRA implies DARA, this property in present in the model.
} 
vulnerable to negative income shocks. Firstly, this feature seems quite intuitive from pure introspection. ${ }^{3}$ Secondly, empirical evidence also confirms the fact that risk aversion decreases with income. For example, Rosenzweig and Binswanger (1993) show that poorer farmers choose less risky crops, even if this means sacrificing expected profits, so that to mitigate weather risks. Chiappori and Paiella (2008) found relative risk aversion to be constant for a panel of Italian households. More strikingly, Ogaki and Zhang (2001) find support for the even stronger property of decreasing relative risk aversion (DRRA) using data from Pakistani and Indian households. ${ }^{4}$

The main focus of this paper is on the evolution of informational asymmetries alongside the process of development and its implications for risk-taking and growth. Banerjee and Newman (1991), Acemoglu and Zilibotti (1999), and Newman (2007) have also investigated these phenomena, although their focus is on the ability to provide correct incentives to entrepreneurs in the presence of moral hazard related to effort unobservability. ${ }^{5}$ In that respect, by studying the problem of entrepreneurial selection when talented entrepreneurs cannot be easily screened from the whole population by outside financiers, my paper presents new insights regarding the interplay between insurance, industrialisation and growth. ${ }^{6}$

Another strand of related literature is that on credit market imperfections and development [e.g., Banerjee and Newman (1993), Galor and Zeira (1993), Aghion and Bolton (1997), Piketty (1997), Lloyd-Ellis and Berhardt (2000), Ghatak and Jiang (2002), and Mookherjee and Ray (2002)], where typically credit constraints prevent the poor from starting up investment projects or accumulating human capital, which would be optimal in a first-best

\footnotetext{
${ }^{3}$ This is explicitly acknowledged in Kimball (1990) who asserts, "DARA is almost universally considered a reasonable assumption, or even obligatory assumption, since [it implies] investing more in risky securities as one becomes wealthier", footnote 25 therein.

${ }^{4}$ Evidence of DRRA is also found in studies that look at households data on asset holdings; e.g., Morin and Fernandez Suarez (1993) for Canada, Guiso et al (1996) for Italy, and Blake (1996) for the UK.

${ }^{5}$ Greenwood and Jovanovic (1990), Saint-Paul (1992), and Acemoglu and Zilibotti (1997) also study the effects of imperfect risk sharing on development. However, in all these papers information is symmetric and imperfect insurance arises due to the presence of technological non-convexities.

${ }^{6} \mathrm{~A}$ lengthier discussion of the relation between my paper and the previous literature on informational asymmetries in development is relegated to the conclusion.
} 
world. Here, I focus on unwillingness to invest in entrepreneurial projects under imperfect risk sharing, rather than on the incapacity to do so owing to lack of initial funds. Arguably, both insurance and credit are relevant for sustaining a process of development -as stressed by Banerjee (2000)-, and my paper and those articles should, accordingly, be viewed as complementary to each other.

Lastly, concerning the market failure studied in this paper; this is clearly not new. In particular, the negative effects of adverse selection on the operation of financial markets have long been investigated by both the corporate finance literature [e.g., Leland and Pyle (1977) and Myers and Majluf (1984)] and the credit rationing literature [e.g., Jaffe and Russell (1976) and Stiglitz and Weiss (1981)]. The contribution of this paper is that it shows how this adverse selection problem can severely menace the process of development. Furthermore, the informational asymmetry arises endogenously during the process of development, as it is inherently associated with the heterogeneity of entrepreneurial skills in the population. ${ }^{7}$

The rest of the paper is organised as follows. Section II describes the set up of the model. Section III characterises the static equilibrium under imperfect risk sharing. Section IV analyses the dynamics of the economy, specifying the conditions under which poverty traps may arise. Section $\mathrm{V}$ discusses some technological aspects that can affect the likelihood of poverty traps. Section VI concludes. Omitted proofs are provided in Appendix A.

\section{Environment}

Consider an overlapping-generations small open economy in which life evolves over a discretetime infinite horizon. Individuals in the economy may live up to two periods (young and old). In every period $t$ a continuum of individuals with mass normalised to 1 is born. All individuals are born with an identical endowment of 1 unit of time, which they use entirely

\footnotetext{
${ }^{7}$ In the paper, adverse selection arises alongside industrialisation, and remains unaltered during the process of development. More precisely, growth does not per se mitigate the adverse selection problem (although, it does manage to help overcome it). A related paper, Jaimovich (2009), studies how increasing sectoral diversification may help alleviate a similar adverse selection problem by improving the self-selection of skills.
} 
to work while they are young. In the second period of life, when individuals are old, they can choose either to retire or to become entrepreneurs. Retiring yields zero income.

Young agents may choose to work in two different occupations: they can work in the agricultural sector, becoming independent labourers working in a communal plot of land; alternatively they can work in the manufacturing sector as employees for the old entrepreneurs, earning a fixed wage $\omega$.

Any old agent may decide to become an entrepreneur. However, not all them would be equally good as entrepreneurs. In particular, there exist two types of entrepreneur indexed by $T \in\{B, G\}$, where $B(G)$ stands for bad types (good types). The good types represent a fraction $\eta \in(0,1)$ of the population and possess higher expected productivity as entrepreneurs than the bad types do, who comprise the remaining fraction $(1-\eta)$. The fractions of good and bad types are constant over time. Types are assumed to be private information.

\section{Preferences}

Individuals only derive utility from consumption when they are old. However, individuals need to consume (at least) one unit of consumption good while they are young in order to reach the second period of their lives. As a result, all the income above one they earn while young will be saved and invested to provide for future consumption.

Conditional on reaching the second period of life, the utility achieved by individual $i$ born in $t$ is given by:

$$
u_{i, t}=\ln \left(c_{i, t+1}\right)
$$

where $c_{i, t+1}$ denotes the consumption in $t+1$ by agent $i$ born in $t$. Logarithmic Bernoulli utility implies that individuals are risk averse with CRRA equal to $1 .^{8}$

\footnotetext{
${ }^{8}$ None of the main insights of the paper strictly depend either on the need to consume 1 unit during youth or on the utility function being logarithmic. See Appendix B for a description of the workings of the model under a more general CRRA utility function and in which individuals consume nothing while they are young.
} 


\section{Technology: Agricultural and Manufacturing Sectors}

The total amount of land in the economy is fixed. Hence, aggregate production in the agricultural sector $(Y)$ varies only with the total mass of agricultural labourers $(L)$, according to the following production function: $Y(L)=L^{\alpha}$, where $\alpha \in(0,1)$. There are no property rights over land, thus each agricultural labourer obtains as income the average output $y(L) \equiv$ $Y(L) / L$, which is strictly decreasing in $L$.

Production in the manufacturing sector requires 1 unit of entrepreneurial skill (coming from the old generation) and raw labour (coming from the young generation). The return of the entrepreneurial projects is random, subject to an idiosyncratic shock. There are only two possible outcomes for the projects: success or failure. If an old agent hires $l$ units of young labour at the beginning of period $t$; then, in the event of success, the project yields $\rho l$ units of output at the end of $t$, where $\rho>0$. On the other hand, in the event of failure, the project yields 0 output regardless of $l$. A good-type entrepreneur fails with probability $\phi_{G}=\phi \in(0,1)$, whereas a bad type fails with probability equal to $\phi_{B}=1$. Project outcomes are assumed publicly observable at zero cost (this implies that any contract whose payment is conditional on ex post project outcomes can be enforced by an outside court and will always be honoured in equilibrium). Each entrepreneur is a price taker in the labour market and must thus pay the market wage $\omega$ for each unit of labour hired. I assume entrepreneurs must pay workers' wages at the beginning of the production process, implying that the amount $\omega l_{i}$ equals the total investment by entrepreneur $i$.

Young agents will naturally choose the occupation (agricultural labourer or manufacturing employee) that yields the higher income. As a result, since the labour market is competitive, and Inada conditions imply there will always be a positive measure of agricultural labourers; the young will spread themselves among the two occupations such that they are indifferent between them, that is, such that $\omega=L^{\alpha-1}$ holds. 


\section{Financial Markets}

All financial transactions between natives and with the rest of the world are mediated by specialised firms called financial intermediaries (or, for brevity, financiers). The local financial market is perfectly competitive and the financial intermediaries enjoy perfect access to international capital markets. Since the economy is small, financiers face then a perfectly elastic supply of loanable funds in the international capital markets at the international (net) interest rate $r=0$.

Financial intermediates may invest in a riskless asset yielding zero (net) return; this asset could be thought of as either storage or lending to the rest of the world. They may also finance entrepreneurial projects. They do so by buying shares in those projects. More precisely, financiers offer to buy a certain amount of shares of a specific project at a prearranged price. Each of those shares entitles the shareholder to $\rho$ units of output in case of success, while in the case of failure shares yield 0 income.

More formally, a financier offers a contract $\left[\mu_{i}, p_{i}\right]$ to entrepreneur $i$, which specifies the number of shares $\mu_{i}$ of project $i$ that the financier would buy at the unit price $p_{i} .{ }^{9}$ Entrepreneurs could (in principle) receive contract offers from several financial intermediaries. Accordingly, let $\mathfrak{Q}_{i}$ denote the set of all financial contracts offered to the entrepreneur $i$.

When referring to the financial markets, the equilibrium concept used throughout this paper will be that defined in Rothschild and Stiglitz (1976). Because of the well-known potential equilibrium (non-)existence problem, the fraction of bad types $(1-\eta)$ will accordingly be assumed to be large enough so as to ensure the existence of such an equilibrium.

Remark: Financiers could also provide funds to entrepreneurs by means of credit contracts at the interest rate $r=0$. Yet, as will become clearer in the next section, in equilibrium no entrepreneur will desire to borrow from financiers via credit contracts. Intuitively, selling shares to financiers strictly dominates the use of credit, as equity markets allow not only the raising of funds but also the provision of insurance.

\footnotetext{
${ }^{9}$ An implicit assumption is the fact that contracts cannot be negotiated in advance; in other words, a financial contract agreed in period $t$ only covers events occurring during that period.
} 


\section{Static Equilibrium Analysis}

Consider the problem faced by the agent $i$ of type $T$ born in $t-1$. Suppose this agent has earned income equal to $\omega_{t-1} \geq 1$ while he was young. His disposable income at the beginning of $t$ then equals $\omega_{t-1}-1$. (To reduce notation, $\omega_{t-1} \geq 1$ will always be assumed unless otherwise explicitly noted). ${ }^{10}$ Given $\omega_{t}$, this agent solves the following optimisation problem, where $s_{i}$ denotes the amount lent to financiers at the interest rate $r=0:{ }^{11}$

$$
\begin{gathered}
\max _{s_{i, t}, l_{i, t},\left[\mu_{i, t}, p_{i, t}\right]}: E\left(u_{i, t-1}\right)=\phi_{T} \ln \left(s_{i, t}\right)+\left(1-\phi_{T}\right) \ln \left(s_{i, t}+\rho l_{i, t}-\rho \mu_{i, t}\right) \\
\text { subject to: } s_{i, t}+\omega_{t} l_{i, t}=\left(\omega_{t-1}-1\right)+p_{i, t} \mu_{i, t}, \\
{\left[\mu_{i, t}, p_{i, t}\right] \in \mathfrak{Q}_{i, t}, \quad \text { and } \quad l_{i, t} \geq 0 .}
\end{gathered}
$$

An equilibrium in period $t$ is given by: $i)$ a portfolio allocation $\left(s_{i, t}, l_{i, t},\left[\mu_{i, t}, p_{i, t}\right]\right)$ by each agent $i$ born in $t-1, i i)$ a set of financial contracts $\mathfrak{Q}_{i, t}$ offered to each agent $i$ born in $t-1$, and $i i i)$ a market wage $\omega_{t}$, such that:

1. Each portfolio allocation $\left(s_{i, t}, l_{i, t},\left[\mu_{i, t}, p_{i, t}\right]\right)$, solves (2) subject to (3) and (4).

2. Given the set of contracts $\mathfrak{Q}_{i, t}$ : $(i)$ No contract belonging to $\mathfrak{Q}_{i, t}$ makes negative expected profits, and $(i i)$ there exists no other feasible contract $\mathfrak{z}$, such that $\mathfrak{z} \notin \mathfrak{Q}_{i, t}$, which, if offered in addition to $\mathfrak{Q}_{i, t}$, would make positive expected profits.

3. The labour market clears, i.e. $\int_{0}^{1} l_{i, t} d i=1-L_{t}$, at a wage equal to the average productivity in the agricultural sector, i.e. $\omega_{t}=L_{t}^{\alpha-1}$.

\footnotetext{
${ }^{10}$ In any case, as it will be formally proved in Section IV, $\omega_{t-1} \geq 1$ will always hold in equilibrium within a full dynamic setting - see Lemma 1 in that section.

${ }^{11}$ Notice that the agent $i$ may wish to optimally set $l_{i}=0$, which we can interpret as retiring when old. Notice also that the optimisation problem does not preclude $s_{i}<0$ (that is, borrowing via credit is not ruled out). However, unboundedness implies that $s_{i}>0$ will always hold in the optimum.
} 


\section{Incentive-Compatible Contracts and Entrepreneurial Investment}

Financial intermediaries will screen types by restricting the amount of shares on their own projects that entrepreneurs are allowed to sell. More precisely, the level of $\mu_{t}$ will be set low enough so as to dissuade any bad-type entrepreneur from mimicking the behaviour of a good-type entrepreneur. The drawback of this screening policy is that by limiting $\mu_{t}$ below first-best levels (which means that entrepreneurial failure is not fully insured), financiers might also end up discouraging first-best investment by the good types.

Perfect competition in the financial markets implies that in a Rothschild-Stiglitz equilibrium, any good type should receive a price $p_{t}=(1-\phi) \rho$ for each of the shares sold to the financiers (that is, each share must command a price equal to its expected payoff when the project is undertaken by a good type). Denote by $l_{t}^{*}$ the level of $l_{t}$ that solves (2) - (4) for a good type. Note that a bad type trying to "disguise" himself as a good type should also hire $l_{t}^{*}$ workers (otherwise, he would be assessed as a bad type by the financiers and would not be offered the contract devised for the good types). Incentive-compatibility for any bad type born in $t-1$ requires then the following to hold:

$$
\ln \left(\omega_{t-1}-1\right) \geq \ln \left[\left(\omega_{t-1}-1\right)-\omega_{t} l_{t}^{*}+(1-\phi) \rho \widehat{\mu}_{t}\right]
$$

where $\widehat{\mu}_{t}$ denotes the maximum number of shares that entrepreneurs can sell to the financiers at the unit price $(1-\phi) \rho$, having hired $l_{t}^{*}$ workers. ${ }^{12}$

The right-hand side of (5) shows the utility achieved by an bad-type entrepreneur when he replicates the portfolio allocation chosen by a good type. The left-hand side equals the utility that any agent would get by investing all his first-period disposable income in the safe asset at $r=0$ (that is, by setting $s_{t}=\omega_{t-1}-1$ ); this investment policy represents the outside option available to the old agents in the economy.

The incentive-compatibility constraint (5) can also be re-expressed as follows:

$$
\omega_{t} l_{t}^{*} \geq(1-\phi) \rho \widehat{\mu}_{t}
$$

\footnotetext{
${ }^{12}$ Implicit in (5) is the fact that the upper bound on shares, $\widehat{\mu}_{t}$, binds in the optimum. This result is formally proved in Appendix A - see there Derivation of Equation (9).
} 
which has a very intuitive interpretation. It requires that, in the state of failure, entrepreneurs should be compensated at most for the total amount invested in the project, $\omega_{t} l_{t}^{*}$; this is the maximum compensation (or insurance) that can be provided to the good types without attracting the bad types as well (who fail with probability 1).

From the discussion above, it follows that the optimisation problem (2) - (4) for a good type born it $t-1$ can be rewritten as follows:

$$
\begin{aligned}
\max _{l_{t} \geq 0, \mu_{t} \geq 0}: E\left(u_{t-1}\right)=\phi & \ln \left[\left(\omega_{t-1}-1\right)+(1-\phi) \rho \mu_{t}-\omega_{t} l_{t}\right] \\
& +(1-\phi) \ln \left[\left(\omega_{t-1}-1\right)+\left(\rho-\omega_{t}\right) l_{t}-\phi \rho \mu_{t}\right]
\end{aligned}
$$

subject to: $\mu_{t} \leq \widehat{\mu}_{t}$.

The solution of the problem (7) - (8), together with the incentive compatibility constraint (6), yields the following result (the derivation of (9) is provided in Appendix A):

$$
l_{t}^{*}= \begin{cases}\frac{1-\phi}{\phi} \frac{1}{\omega_{t}}\left(\omega_{t-1}-1\right) & \text { if }(1-\phi) \rho>\omega_{t}, \\ {\left[0, \frac{1-\phi}{\phi} \frac{1}{\omega_{t}}\left(\omega_{t-1}-1\right)\right]} & \text { if }(1-\phi) \rho=\omega_{t}, \\ 0 & \text { if }(1-\phi) \rho<\omega_{t} .\end{cases}
$$

The expression in (9) summarises the risk-taking behaviour of the good types born in $t-1$ when adverse selection prevents full risk-sharing via equity markets. A crucial property of $(9)$ is that - whenever $(1-\phi) \rho>\omega_{t}$ - entrepreneurial investment by the good types (i.e., $\left.\omega_{t} l_{t}^{*}\right)$ is an increasing function of their initial income, $\omega_{t-1}$. This is due to the fact that preferences display CRRA, which in turn implies DARA. When preferences exhibit DARA, the total amount invested in riskier assets is increasing in the individual's initial income. Since in this model part of the idiosyncratic risks must be borne by the entrepreneurs so as to comply with (6), investing in the entrepreneurial projects entails a risky decision and will thus increase with the initial income of the good types.

The equation (9) can alternatively be seen as the individual labour demand function. As it is the usual case, the labour demand is decreasing in the wage $\omega_{t}$. Notice, however, that 
the reason for this is not the standard decreasing marginal productivity of labour, but the fact that entrepreneurs have limited possibilities to spread risks.

\section{Equilibrium in the Labour Market}

The last variable that remains to be determined in order to characterise fully the equilibrium in period $t$ is the market wage, $\omega_{t}$. This variable is pinned down in the labour market, where the labour supply derives from the occupational choice of the young generation and the labour demand results from adding up (9) across all good types born in $t-1$. To avoid the trivial case in which no manufacturing sector ever arises in equilibrium, I impose the following condition:

\section{Assumption 1. $(1-\phi) \rho>1$}

The equilibrium in the labour market in period $t$ is determined by the intersection of the labour demand $\left(l_{t}^{D}\right)$ and labour supply $\left(l_{t}^{S}\right)$ correspondences, where:

$$
\begin{aligned}
& l_{t}^{D}= \begin{cases}\eta \frac{1-\phi}{\phi} \frac{1}{\omega_{t}}\left(\omega_{t-1}-1\right) & \text { if }(1-\phi) \rho>\omega_{t}, \\
{\left[0, \eta \frac{1-\phi}{\phi} \frac{1}{\omega_{t}}\left(\omega_{t-1}-1\right)\right]} & \text { if }(1-\phi) \rho=\omega_{t}, \\
0 & \text { if }(1-\phi) \rho<\omega_{t} .\end{cases} \\
& l_{t}^{S}=\left\{\begin{array}{cl}
0 & \text { if } \omega_{t}<1, \\
1-\omega_{t}^{-\frac{1}{1-\alpha}} & \text { if } \omega_{t} \geq 1 .
\end{array}\right.
\end{aligned}
$$

Notice that when $\omega_{t} \geq 1, l_{t}^{S}=1-y^{-1}\left(\omega_{t}\right)$, where $y^{-1}(\cdot)$ is the inverse function of the average agricultural output $y(L)$. This is the case because when $\omega_{t} \geq 1$, the young must be indifferent between working in the agricultural or in the manufacturing sector, hence $\omega_{t}=y\left(1-l_{t}^{S}\right)$.

Let $l_{t}^{*}$ and $\omega_{t}^{*}$ denote henceforth the labour market equilibrium values of $l$ and $\omega$, and define $\hat{\omega} \equiv 1+\left[1-[(1-\phi) \rho]^{-\frac{1}{1-\alpha}}\right] \rho \phi / \eta$, where notice that $\hat{\omega}>1$.

\section{Proposition 1 (Labour Market Equilibrium).}

(i) Whenever $\omega_{t-1}>1$, the equilibrium wage $\omega_{t}^{*}$ is a non-decreasing function of $\omega_{t-1}$. In 
particular, if $\omega_{t-1}>1, \omega_{t}^{*}\left(\omega_{t-1}\right):(1, \infty) \rightarrow(1,(1-\phi) \rho]$, such that: a) for all $\omega_{t-1} \in(1, \hat{\omega})$, $\omega_{t}^{*}<(1-\phi) \rho$ and $\omega_{t}^{*}$ is strictly increasing in $\omega_{t-1}$; b) for all $\omega_{t-1} \geq \hat{\omega}, \omega_{t}^{*}=(1-\phi) \rho$. Furthermore, whenever $\omega_{t-1}>1, l_{t}^{*}=1-\left(1 / \omega_{t}^{*}\left(\omega_{t-1}\right)\right)^{1 /(1-\alpha)}$, thus $l_{t}^{*} \in(0,1)$. (ii) If $\omega_{t-1} \in[0,1]$, then $\omega_{t}^{*} \in[0,1]$ and $l_{t}^{*}=0$.

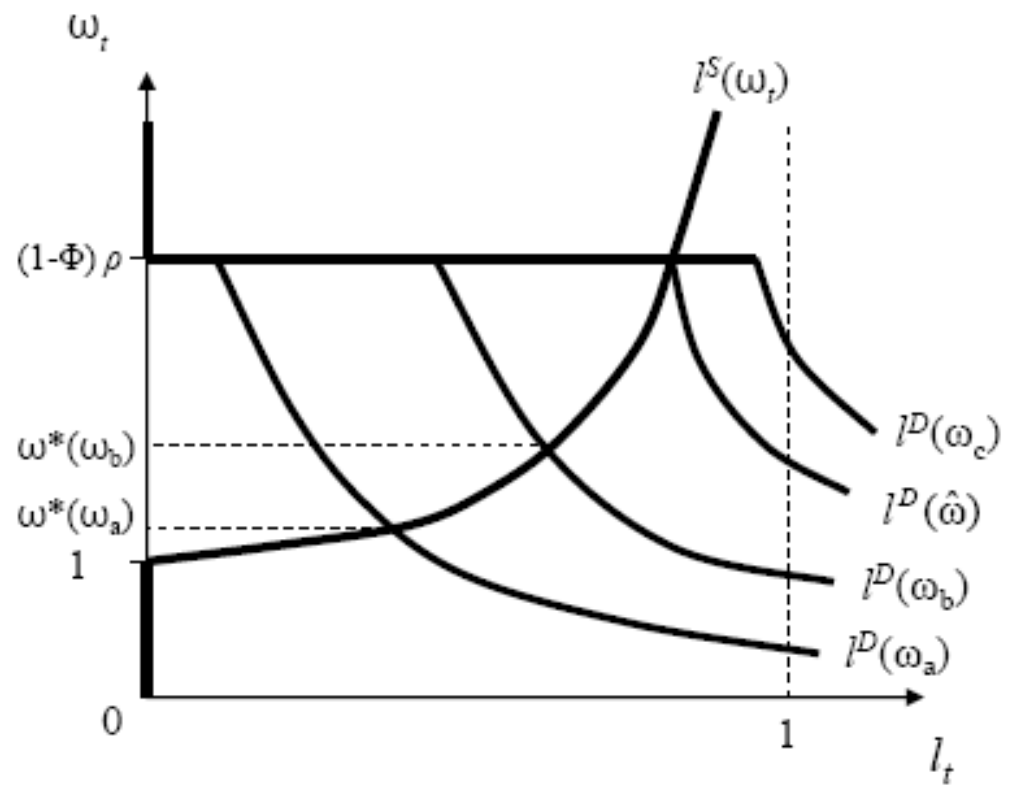

FIGURE 1: Labour Market Equilibrium Labour market equilibrium at four different levels of $\omega_{\mathrm{t}-1}$

Proposition 1 describes how $\omega_{t}^{*}$ is influenced by the initial income of the previous generation, $\omega_{t-1}$. Figure 1 illustrates the results in the proposition for four different values of $\omega_{t-1}$, namely: $\omega_{a}, \omega_{b}, \hat{\omega}$ and $\omega_{c}$ (where, $\left.1<\omega_{a}<\omega_{b}<\hat{\omega}<\omega_{c}\right){ }^{13}$ Since a larger $\omega_{t-1}$ leads to higher risk-taking by the good types, labour demand turns out to be (weakly) increasing in $\omega_{t-1}$. As labour demand increases with $\omega_{t-1}$, the equilibrium wage $\omega_{t}^{*}$ must rise to attract some additional young agents from the agricultural sector to the manufacturing sector. This positive impact of $\omega_{t-1}$ and $\omega_{t}^{*}$ represents the key mechanism that may give rise to poverty traps and multiple long-run equilibria in the following section.

\footnotetext{
${ }^{13}$ Although not drawn in Figure 1, when $\omega_{t-1} \in[0,1]$ the labour demand is a straight line along $l_{t}=0$ (i.e., $l_{t}^{D}(\cdot)$ coincides with the vertical axis). As a result, for all $\omega_{t-1} \in[0,1], l_{t}^{D}\left(\omega_{t-1}, \omega_{t}\right)$ and $l_{t}^{S}\left(\omega_{t}\right)$ intersect each other at $l_{t}=0$, along the whole segment $\omega_{t} \in[0,1]$; which is the result (ii) in Proposition 1.
} 


\section{Dynamic Analysis}

In order to characterise the dynamic behaviour of the economy, it proves convenient to start by stating the following result:

Lemma 1. $\omega_{\tau} \in[1,(1-\phi) \rho]$, regardless of the value of $\omega_{\tau-1}$, for all $\tau \in\{1,2, \ldots \infty\}$.

Proof. Firstly, notice that the minimum value $\omega_{\tau}$ can take in equilibrium is 1 , as this is the average productivity of the agricultural sector when $L_{\tau}=1$. Secondly, observe from (10) that if $\omega_{\tau}>(1-\phi) \rho$, then $l_{\tau}^{D}=0$. As a result, all the young population alive in $\tau$ should work in the agricultural sector, whose average productivity would then equal 1. Therefore, $\omega_{\tau}>(1-\phi) \rho$ cannot hold in equilibrium either.

From Lemma 1, it follows that we can restrict the state space of $\omega_{t-1}$ to the interval $[1,(1-\phi) \rho]$. When $\omega_{t-1} \in(1,(1-\phi) \rho]$, the equilibrium in the labour market encompasses $l_{t}^{*} \in(0,1)$. Therefore, young agents alive in $t$ must be indifferent between the two occupations, earning $\omega_{t}=y\left(1-l_{t}^{*}\right)$. On the other hand, when $\omega_{t-1}=1$, labour demand by entrepreneurs falls to zero, and all the young generation must thus work in the agricultural sector, earning income $\omega_{t}=y(1)=1$.

Let $\bar{\omega} \equiv \min \{\hat{\omega},(1-\phi) \rho\}$. We can thus write down the Law of Motion for $\omega_{t}$ as follows:

Law of Motion: $\left\{\begin{array}{l}\Psi\left(\omega_{t-1}, \omega_{t}\right) \equiv \frac{1-\phi}{\phi} \frac{\eta}{\omega_{t}}\left(\omega_{t-1}-1\right)+\left(\frac{1}{\omega_{t}}\right)^{\frac{1}{1-\alpha}}-1=0, \text { if } \omega_{t-1} \in[1, \bar{\omega}] \text {; } \\ \omega_{t}=(1-\phi) \rho, \text { if } \omega_{t-1} \in(\bar{\omega},(1-\phi) \rho] \text { and }(\bar{\omega},(1-\phi) \rho] \neq \emptyset .\end{array}\right.$

If $\hat{\omega} \geq(1-\phi) \rho$, then the implicit function $\Psi\left(\omega_{t-1}, \omega_{t}\right)=0$ alone depicts the dynamic behaviour of $\omega_{t}$. Instead, if $\hat{\omega}<(1-\phi) \rho$, the dynamics of $\omega_{t}$ are determined by $\Psi\left(\omega_{t-1}, \omega_{t}\right)=$ 0 when $\omega_{t-1} \in[1, \hat{\omega}]$, while $\omega_{t}=(1-\phi) \rho$ when $\omega_{t-1} \in(\hat{\omega},(1-\phi) \rho]$.

Lemma 2. $\Psi\left(\omega_{t-1}, \omega_{t}\right)=0$ yields a mapping $\omega_{t}\left(\omega_{t-1}\right):[1, \bar{\omega}] \rightarrow[1,(1-\phi) \rho]$, which is strictly increasing and strictly convex in $\omega_{t-1}$. 
The value of $\omega_{t}$ is increasing in $\omega_{t-1}$-for $\omega_{t-1} \in[1, \bar{\omega}]$ - because entrepreneurial investment in $t$ rises with $\omega_{t-1}$; as explained earlier, this is a direct consequence of preferences with DARA. On the other hand, the convexity of $\omega_{t}\left(\omega_{t-1}\right)$ is related to the fact that average agricultural productivity is decreasing in $L$, which translates into a convex labour supply function (as that plotted in Figure 1). More intuitively, as labour demand grows in the manufacturing sector, each additional worker that needs to be drawn from the agricultural sector becomes increasingly expensive, because agricultural productivity rises as $L$ diminishes.

Given the specific parametric configuration, we can find three different types of dynamics in terms of their qualitative features and their long-run equilibria.

\section{Proposition 2 (Long-Run Equilibria).}

(i) Suppose $\phi /[\eta(1-\phi)] \in(1-\alpha, 1)$. Then, there exists a threshold level $\bar{\rho}(\alpha)>1 /(1-\phi)$, where $\bar{\rho}^{\prime}(\alpha)>0$, such that: $\forall \rho>\bar{\rho}(\alpha)$, there exist two (locally) stable stationary equilibria, namely, $\omega=1$ and $\omega=(1-\phi) \rho$.

(ii) Suppose $\phi /[\eta(1-\phi)] \geq 1$. Then, the only stable stationary equilibrium in the economy is $\omega=1$. Furthermore, if $\phi /[\eta(1-\phi)] \in(1-\alpha, 1)$ holds, but $\rho \leq \bar{\rho}(\alpha)$, then the only stable stationary equilibrium in the economy is still $\omega=1$.

(iii) Suppose $\phi /[\eta(1-\phi)] \leq 1-\alpha$. Then, the only stable stationary equilibrium in the economy is $\omega=(1-\phi) \rho$.

Proposition 2 shows that when $\phi /[\eta(1-\phi)] \in(1-\alpha, 1)$, two (locally) stable long-run equilibria may coexist in the economy. First, we have a poverty trap in which $\omega=1$ and $l=0$; in other words, an equilibrium where the economy remains poor and fully agricultural. Second, there might be a high income long-run equilibrium in which $\omega=(1-\phi) \rho$ and $l \in(0,1)$, so part of the economy works in the manufacturing sector. This equilibrium arises when $\rho$ is large enough; in other words, when the manufacturing sector is sufficiently productive. Intuitively, Proposition 1 shows that (within a certain range) a larger $\omega_{t-1}$ leads to a higher $\omega_{t}$; when $\rho$ is sufficiently large, the entrepreneurial projects are so productive that the positive impact of $\omega_{t-1}$ on $\omega_{t}$ extends over an interval long enough that an additional (stable) stationary point arises in the model. 


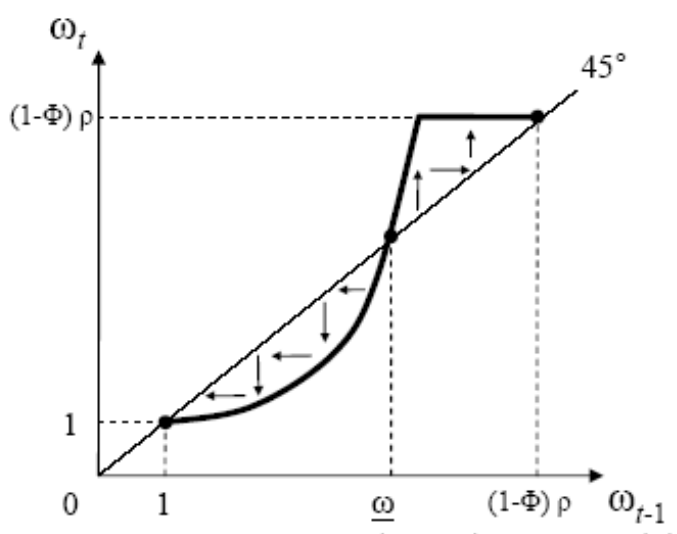

(a) case (i): $\frac{\phi}{\eta(1-\phi)} \in(1-\alpha, 1) \wedge \rho>\bar{\rho}(\alpha)$

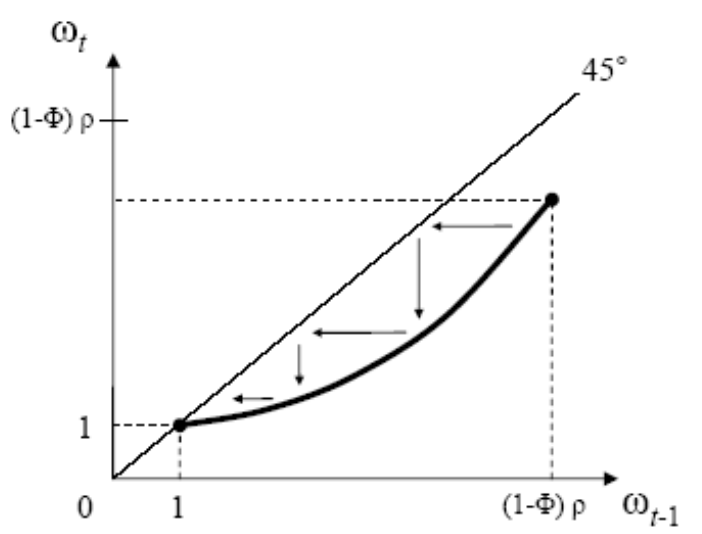

(b) case (ii): $\frac{\phi}{\eta(1-\phi)} \geq 1$ or $\frac{\phi}{\eta(1-\phi)} \in(1-\alpha, 1) \wedge \rho<\bar{\rho}(\alpha)$

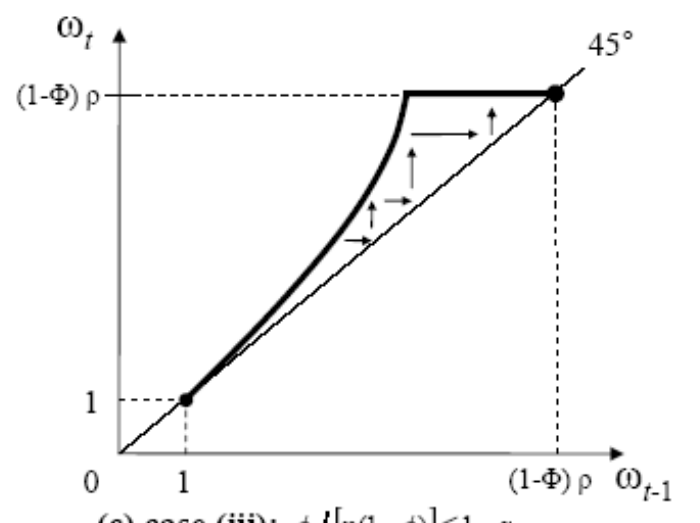

(c) case (iii): $\phi /[\eta(1-\phi)] \leq 1-\alpha$

FIGURE 2: Initial Income Dynamics

Figure 2 illustrates the three distinct cases presented in Proposition 2. In (a), a situation leading to multiple long-run equilibria is shown. Whenever $\omega_{0}>\underline{\omega}, \omega_{t}$ will be continuously growing over time, converging monotonically towards $\omega=(1-\phi) \rho$. During this process, $l_{t}^{*}$ will also be rising, meaning both that the manufacturing sector is expanding and that risk-taking by the entrepreneurs is increasing. On the other hand, if $\omega_{0}<\underline{\omega}$, the economy will converge towards $\omega=1$ (a poverty trap), where $l_{t}^{*}=0$. Essentially, in $\omega=1$ individuals are so poor that they completely shy away from risky projects as a way to avoid the low levels of consumption that would prevail in the event of failure. This, in turn, implies that manufacturing labour demand falls to zero; thus, the entire young generation must resort to agricultural production, driving down its average productivity to $y(1)=1 .{ }^{14}$

\footnotetext{
${ }^{14}$ The point $\omega=\underline{\omega}$ is also a stationary equilibrium in Figure 2.(a), but it is unstable.
} 
In Figure 2.(b) the poverty trap represents the unique long-run equilibrium. This situation arises when the failure probability $\phi$ is sufficiently large. In other words, when entrepreneurial projects are sufficiently risky, imperfect risk sharing prevents the economy from breaking away from the poverty trap in $\omega=1$.

Finally, in Figure 2.(c), a case in which for any $\omega_{0}>1$ the economy converges to $\omega=$ $\rho(1-\phi)$ in the long run is plotted. In contrast with the example in Figure 2.(b), this situation appears when $\phi$ is small enough. Intuitively, when the failure risk is sufficiently low, imperfect risk pooling does not discourage entrepreneurial investment too severely, allowing the economy to grow over time and eventually reach $\omega=\rho(1-\phi)$.

\section{Discussion: the likelihood of poverty traps}

\section{The Risk/Return Trade-Off}

From Figure 2 it follows that different economies might experience divergent dynamics, depending on the specific parametric configurations (in terms of $\phi, \eta, \alpha$ and $\rho$ ) that apply. Of particular interest is case $(i)$, from where it follows that middle-income economies are those especially prone to display divergent dynamics, even when having started off with similar incomes per capita. ${ }^{15}$

From (12), we can observe that the stationary point $\underline{\omega}$ that divides the two attraction sinks in Figure 2.(a) stems from the following equation:

$$
\eta \frac{1-\phi}{\phi}=\frac{\underline{\omega}-\underline{\omega}^{-\frac{\alpha}{1-\alpha}}}{\underline{\omega}-1} \equiv \Gamma(\underline{\omega}) .
$$

Equation (13) implies, first, that $\underline{\omega}$ is independent of the specific value of $\rho$-as long as $\rho>\bar{\rho}(\alpha)$, so that $\underline{\omega}<(1-\phi) \rho$ actually exists-. A second observation that follows from (13) is that $\underline{\omega}$ rises with the risk parameter $\phi$ (i.e., $\partial \underline{\omega} / \partial \phi>0$ ); this is the case because the left-hand side is decreasing in $\phi$ and $\Gamma^{\prime}(\underline{\omega})<0$. In that regard, when case $(i)$ applies,

\footnotetext{
${ }^{15}$ Evidence of the world income distribution converging towards a bimodal distribution is provided in Quah (1996). Furthermore, Quah (1993) shows that divergent long-run dynamics are systematically observed among economies whose incomes were initially located around the world average.
} 
middle-income economies are especially susceptible to the risk/return trade-off intrinsic to different investment projects. In particular, middle-income economies that have access to relatively safe technologies, even if they were less productive on expectation, might be in better position to sustain long-run growth than those which can only invest in relatively risky and highly productive projects.

\section{Agricultural Productivity}

An important feature of the model is the fact that the poverty trap is associated with an agricultural economy. One interesting question that arises is then: is a more productive agricultural sector more or less conducive to a process of long-run growth and modernisation?

The answer to the former question is not at all obvious a priori since higher agricultural productivity encompasses two counteracting effects in the model. On the one hand, it increases the incomes of future generations, enhancing thus their willingness to take on risky investment projects (a wealth effect). On the other hand, it makes it harder to attract workers to the manufacturing sector, raising wages in the economy which in turn reduces entrepreneurial profits (a general equilibrium effect).

A small alteration to the previous model can help shed some light on the relative strengths of each of those two effects when the possibility that an economy gets stuck in a poverty trap is maintained. Let the labour supply (11) be now:

$$
l_{t}^{S}=\frac{1}{A}\left[1-\left(\frac{1}{\omega_{t}}\right)^{\frac{1}{1-\alpha}}\right], \quad \text { if } \omega_{t} \geq 1, \quad \text { where } A \geq 1 .
$$

The parameter $A$ in (14) can be interpreted as an agricultural productivity parameter (the higher $A$, the more productive the agricultural sector is). The general equilibrium effect is reflected in that the larger $A$, the higher the wage $\omega_{t}$ that is required to attract a given supply of workers to the manufacturing sector. Notice too that (14) keeps the property that $l_{t}^{S}=0$ for $\omega_{t}=1$. As a consequence, the stationary point $\omega=1$ still survives to $A>1 .{ }^{16}$

\footnotetext{
${ }^{16}$ Equation (14) stems from an agricultural production function with average output: $y(L)=$ $[A L-(A-1)]^{\alpha-1}$, which is increasing in $A$ for any $L<1$. As before, $y(1)=1$. A minor caveat with this specification is the fact that $y\left(1-A^{-1}\right)=\infty$; hence average output goes to infinity before $L$ reaches
} 
The necessary and sufficient condition for the existence of a stable poverty trap in $\omega=1$

is $\left.\frac{d \omega_{t}}{d \omega_{t-1}}\right|_{\omega_{t-1}=1}<1$. This condition now requires that $\phi /[A \eta(1-\phi)]>1-\alpha$, which becomes harder to comply for larger values of $A$. From that perspective, economies in the vicinity of $\omega_{t}=1$ benefit from increases in agricultural productivity, as this fosters long-run growth through the wealth effect and turns less likely that they end up trapped in $\omega=1$.

Furthermore, a larger $A$ is also conducive to positive long-run dynamics by shrinking the size of the poverty trap attraction sink when case $(i)$ prevails. This last result can be seen from the condition (13) when $A \geq 1$ is allowed, which reads: $[A \eta(1-\phi)] / \phi=\Gamma(\underline{\omega})$, implying that $\partial \underline{\omega} / \partial A<0$.

\section{Endogenous Interest Rate}

So far the interest rate has been taken as exogenous. Although fully endogenising the local interest rate is beyond the scope of this paper, a brief discussion of its potential implications is worth attempting.

Notice that an increase in the interest rate, $r$, means that the expected return of risky projects, $\rho(1-\phi)$, declines relative to that of the safe asset. In that sense, a higher $r$ or a lower $\rho$ should carry similar consequences, as both changes would lead to a portfolio re-allocation with a larger share placed on the safe asset.

One possibility that can be envisaged is $r$ falling along the growth path. This would be the case if $r$ includes a country-risk component (affecting both the lending and borrowing rates), and this risk tends to fall as the economy becomes richer. In this scenario, a declining $r$ should create an additional source of non-convexity in the model, making it more likely to display multiple long-run equilibria.

A different scenario arises if the small economy assumption is dropped, and we let $r$ go up as the economy grows and demands more financing. In this case, an increasing $r$ would actually counteract the wealth effect implicit in the model, dampening (at least partially) the non-convexity implied by (12). My conjecture is that, as long as the interest rate does

zero if $A>1$. In case the reader finds this property a bit bothersome, the rest of the analysis in this subsection restricts the attention to values of $L$ where $y(L)$ is finite and, in particular, relatively low. 
not respond too much to income increases the convex portion of the mapping $\omega_{t}\left(\omega_{t-1}\right)$ should not be completely overturned, at least when $\omega_{t-1}$ still lies in the vicinity of 1 .

\section{Concluding Remarks}

This paper has presented a model in which, along the path of development, the economy evolves from a small-scale rural economy into an entrepreneurial manufacturing one. Such a virtuous sequence of growth is, however, not guaranteed because private information prevents full insurance against idiosyncratic shocks in the manufacturing sector, which may discourage talented individuals from entering that sector.

The model shows that risk-bearing increases with income. This result contrasts with Banerjee and Newman (1991) and Newman (2007), where poorer agents bear the risks, while richer agents choose safer activities. In their models, riskier activities require agents to exert effort, which enters linearly in a separable utility function with decreasing marginal utility of consumption. As a result, it becomes easier to incentivise poorer agents to put higher effort into the risky activity because their marginal utility of consumption relative to their disutility of effort is larger. Empirical evidence strongly supports the notion that initial wealth represents a major factor determining entrepreneurship due to the presence of financial market imperfections - see, for example, Evans and Jovanovic (1989). In that respect, this paper contributes to the past literature by suggesting that adverse selection may represent a key market failure that keeps the poor away from entrepreneurial activities. ${ }^{17}$

Risk-bearing increases during development in Acemoglu and Zilibotti (1999), although the underlying mechanism is quite different from the one featured in this paper. In their

\footnotetext{
${ }^{17}$ A passage in Newman (2007) is worth mentioning here. He states "Since embedding the Knightian theory [of entrepreneurship] into a standard moral hazard framework reveals the fragility of its predictions [regarding risk-bearing], it is natural to ask what happens in the presence of other causes of imperfect insurance." The results of my paper should not be understood as Knightian, though. Adverse selection prevents efficient insurance; hence the rich, who are less risk-averse, take on larger risks. Yet, entrepreneurs here are undertaking a productive task (for which they are particularly talented), and not providing insurance to workers through fixed wages, which seems to be the essence of the Knightian theory.
} 
paper, the amount of decentralised information increases as a by-product of capital accumulation which, in turn, enhances the precision of relative performance schemes within multiple principal-agent relationships and enables principals to provide stronger incentives to agents. Hence, in Acemoglu-Zilibotti, the trade-off between insurance and incentives changes with capital accumulation, favouring incentives over insurance provision as the economy grows. In my paper, it is the change in agents' intrinsic attitudes towards risk as they grow richer that induces further risk-bearing. Hence, the key trade-off here is to do with whether or not less vulnerability to income risk is enough to counterbalance the fact that adverse selection becomes more severe as economies move from agricultural to manufacturing production.

An implication that follows from Acemoglu-Zilibotti is that policies fostering competition are growth enhancing, as they increase the amount of information in the economy. In my paper, in contrast, at early stages of development when individuals are still quite sensitive to imperfect insurance, unfettered competition may not be totally advisable. In particular, unrestricted competition implies that all types of agents may try to undertake entrepreneurial projects, generating adverse selection problems in the financial markets. In that regard, a policy recommendation could be to charge an entry fee for entrepreneurial activities and use the proceeds to pay to those who decide to stay away from those activities, as a way to clean the pool of entrepreneurs.

\section{Appendix A: Omitted Proofs}

Derivation of Equation (9)

Let us first state the following preliminary results:

Lemma A.1. If $(1-\phi) \rho>\omega_{t}$, the constraint $\mu_{t} \leq \widehat{\mu}_{t}$ in problem (7) - (8) must bind.

Proof. Suppose (8) did not bind. In that case, first-order conditions would yield: $\mu_{t}=l_{t}>0$.

But, this means (6) would be violated. Hence, (8) must necessarily bind. ॥

Lemma A.2. Suppose $(1-\phi) \rho>\omega_{t}$. Then, the problem $(7)-(8)$ yields:

$$
l_{t}^{*}=\frac{1}{\omega_{t}}\left[\frac{(1-\phi) \rho-\omega_{t}}{\rho-\omega_{t}}\left(\omega_{t-1}-1\right)+\frac{(1-\phi)^{2} \rho+2 \phi \omega_{t}-\omega_{t}}{\rho-\omega_{t}} \rho \widehat{\mu}_{t}\right]
$$

Proof. Since the constraint $\mu_{t} \leq \widehat{\mu}_{t}$ must bind, we can fix $\mu_{t}=\widehat{\mu}_{t}$ an optimise over $l_{t}$ only. 
As a result, the following first-order condition for $l_{t}$ obtains:

$$
\frac{(1-\phi)\left(\rho-\omega_{t}\right)}{\left(\omega_{t-1}-1\right)+\left(\rho-\omega_{t}\right) l_{t}^{*}-\phi \rho \widehat{\mu}_{t}}-\frac{\phi \omega_{t}}{\left(\omega_{t-1}-1\right)-\omega_{t} l_{t}^{*}+(1-\phi) \rho \widehat{\mu}_{t}}=0 .
$$

Finally, from this expression, (A1) immediately follows after some simple algebra. \|

Lemma A.3. Suppose $(1-\phi) \rho>\omega_{t}$. Then, in equilibrium, $\widehat{\mu}_{t}=\omega_{t} l_{t}^{*} /[\rho(1-\phi)]$.

Proof. Suppose (6) did not bind. In that case, financiers could offer a contract carrying $\mu_{t}>\widehat{\mu}_{t}$, which would still screen out the bad types and that would make all the good types better off. Hence, in equilibrium, $\widehat{\mu}_{t}=\omega_{t} l_{t}^{*} /[\rho(1-\phi)]$ must hold. $\|$

By using the results in Lemmas A.2 and A.3, we can next replace $\widehat{\mu}_{t}=\omega_{t} l_{t}^{*} /[\rho(1-\phi]$ into (A1), to finally obtain $l_{t}^{*}=(1-\phi)\left(\omega_{t-1}-1\right)\left(\phi \omega_{t}\right)^{-1}$ when $(1-\phi) \rho>\omega_{t}$.

Suppose now $\omega_{t}=(1-\phi) \rho$. Replacing $\omega_{t}$ by $(1-\phi) \rho$ into $(5)$, yields $\widehat{\mu}_{t} \leq l_{t}$. In equilibrium, $\widehat{\mu}_{t}=l_{t}$ will hold, for a similar argument as in Lemma A.3. Then, good types will optimally set $\mu_{t}^{*}=l_{t}$, which implies that the optimal $l_{t}^{*}$ can be found by solving: $\max _{l_{t} \geq 0}$ : $\left\{\ln \left(\omega_{t-1}-1\right)\right\}$. This last problem can be trivially maximised by any $l_{t} \geq 0$. In particular, any $l_{t} \in\left[0,(1-\phi)\left(\omega_{t-1}-1\right)\left(\phi \omega_{t}\right)^{-1}\right]$, solves the previous optimisation problem.

Finally, when $(1-\phi) \rho<\omega_{t}, l_{t}^{*}$ trivially equals zero, since by investing all $\left(\omega_{t-1}-1\right)$ in the safe-asset, good types can obtain a higher expected return bearing no risks.

Proof of Proposition 1

Part $(i)$. Inspecting (10) and (11) we can observe that, for all $\omega_{t-1} \in(1, \hat{\omega}), \omega_{t}^{*}$ is pinned down by the following equation:

$$
\eta \frac{1-\phi}{\phi} \frac{1}{\omega_{t}^{*}}\left(\omega_{t-1}-1\right)=1-\left(\frac{1}{\omega_{t}^{*}}\right)^{\frac{1}{1-\alpha}}
$$

as (A2) yields indeed $\omega_{t}^{*} \in(1,(1-\phi) \rho), \forall \omega_{t-1} \in(1, \hat{\omega})$. Next, totally differentiating (A2):

$$
\frac{d \omega_{t}^{*}}{d \omega_{t-1}}=\eta \frac{1-\phi}{\phi}\left[\eta \frac{1-\phi}{\phi} \frac{\omega_{t-1}-1}{\omega_{t}^{*}}+\frac{1}{1-\alpha}\left(\frac{1}{\omega_{t}^{*}}\right)^{\frac{1}{1-\alpha}}\right]^{-1}>0 .
$$

In addition, since $\omega_{t}^{*} \in(1,(1-\phi) \rho)$, from $(11)$ it follows that $l_{t}^{*}=1-\left(1 / \omega_{t}^{*}\left(\omega_{t-1}\right)\right)^{1 /(1-\alpha)}$, for all $\omega_{t-1} \in(1, \hat{\omega})$. Hence, $l_{t}^{*} \in(0,1)$.

Now, let $\omega_{t-1}=\hat{\omega}$ and note that $l_{t}^{S}((1-\phi) \rho)=1-[(1-\phi) \rho]^{-\frac{1}{1-\alpha}}=(\phi \rho)^{-1} \eta(\hat{\omega}-1)$. Plus, observe that: $l_{t}^{S}((1-\phi) \rho)<(\phi \rho)^{-1} \eta\left(\omega_{t-1}-1\right)$ for any $\omega_{t-1}>\hat{\omega}$. Hence, since $l_{t}^{D}=0$ 
for all $\omega_{t}>(1-\phi) \rho$, and $l_{t}^{D}=\left[0,(\phi \rho)^{-1} \eta\left(\omega_{t-1}-1\right)\right]$ for $\omega_{t}=(1-\phi) \rho$; then, for any $\omega_{t-1} \geq \hat{\omega}$, the labour market equilibrium yields $\omega_{t}^{*}=(1-\phi) \rho$ and $l_{t}^{*}=(\phi \rho)^{-1} \eta(\hat{\omega}-1) . \|$

Part $(i i)$. For all $\omega_{t-1} \in[0,1]$, labour demand equals zero. Therefore, in equilibrium, $l_{t}^{S}$ must equal zero too; which requires $\omega_{t}^{*} \in[0,1]$.

Proof of Lemma 2

From $\Psi\left(\omega_{t-1}, \omega_{t}\right)=0$ in $(12)$ we obtain: $\omega_{t-1}=\phi[\eta(1-\phi)]^{-1}\left(\omega_{t}-\omega_{t}^{-\frac{\alpha}{1-\alpha}}\right)$; which after differentiating leads to:

$$
\frac{d \omega_{t}}{d \omega_{t-1}}=\frac{\eta(1-\phi)}{\phi} \frac{1}{1+\frac{\alpha}{1-\alpha} \omega_{t}^{-\frac{1}{1-\alpha}}}>0 .
$$

Next, from (A3), bearing in mind $d \omega_{t} / d \omega_{t-1}>0$ and $\alpha>0$, it immediately follows that: $d^{2} \omega_{t} /\left(d \omega_{t-1}\right)^{2}>0, \forall \omega_{t-1} \in[1, \bar{\omega}]$.

Proof of Proposition 2

Part $(i)$. First of all, notice that the point $\omega_{t}=1$ represents always a stationary point of (12), since $\Psi(1,1)=0$. Next, given Lemma 2 , it follows that a necessary and sufficient condition for $\omega=1$ to be locally stable is that (A3) computed at $\omega_{t-1}=1$ is strictly smaller than 1. Thus, replacing $\omega_{t-1}=\omega_{t}=1$ into (A3), we get: $\left.\frac{d \omega_{t}}{d \omega_{t-1}}\right|_{\omega_{t-1}=1}=[\eta(1-\phi)(1-\alpha)] / \phi$. Therefore, $\phi /[\eta(1-\phi)]>1-\alpha$ implies $\left.\frac{d \omega_{t}}{d \omega_{t-1}}\right|_{\omega_{t-1}=1}<1$.

Second, since $\omega_{t}=(1-\phi) \rho$ for all $\omega_{t-1} \in(\bar{\omega},(1-\phi) \rho]$, whenever this interval is nonempty; in order to show that $\omega_{t}=(1-\phi) \rho$ is also a locally stable stationary equilibrium, it suffices to prove that, under the stipulated conditions, $\hat{\omega}<(1-\phi) \rho$. From the expressions in (10) and (11), we can observe that:

$$
\hat{\omega}<(1-\phi) \rho \Leftrightarrow \underbrace{\eta \frac{1-\phi}{\phi} \frac{(1-\phi) \rho-1}{(1-\phi) \rho}}_{M(\rho)}>\underbrace{1-\left[\frac{1}{(1-\phi) \rho}\right]^{\frac{1}{1-\alpha}}}_{N(\rho, \alpha)} .
$$

From (A4), it follows that:

$$
\begin{gathered}
\lim _{\rho \rightarrow 1 /(1-\phi)} M(\rho)=\lim _{\rho \rightarrow 1 /(1-\phi)} N(\rho, \alpha)=0, \\
\lim _{\rho \rightarrow \infty} M(\rho)=\frac{\eta(1-\phi)}{\phi}>\lim _{\rho \rightarrow \infty} N(\rho, \alpha)=1 .
\end{gathered}
$$


Differentiating $M(\rho)$ and $N(\rho, \alpha)$ with respect to $\rho$, we obtain: $d M / d \rho=\eta / \phi \rho^{2}$, and $\partial N / \partial \rho=[(1-\alpha) \rho]^{-1}[(1-\phi) \rho]^{-\frac{1}{1-\alpha}}$. Therefore:

$$
\frac{d M}{d \rho} \gtreqless \frac{\partial N}{\partial \rho} \Leftrightarrow \frac{\eta(1-\phi)}{\phi}(1-\alpha) \gtreqless\left[\frac{1}{(1-\phi) \rho}\right]^{\frac{\alpha}{1-\alpha}} .
$$

Denote by $\hat{\rho}(\alpha)$ the value of $\rho$ that solves (A7) with strict equality; that is:

$$
\eta \frac{(1-\phi)}{\phi}(1-\alpha) \equiv\left[\frac{1}{(1-\phi) \hat{\rho}}\right]^{\frac{\alpha}{1-\alpha}}
$$

where it can be observed that $\hat{\rho}(\alpha)>1 /(1-\phi)$. Then, the expression in (A7), together with (A8) and the fact that $\phi /[\eta(1-\phi)]>1-\alpha$, imply:

$$
\begin{aligned}
& \text { 1) for all } \rho \in(1 /(1-\phi), \hat{\rho}(\alpha)) \text { : } d M / d \rho<\partial N / \partial \rho \\
& \text { 2) for all } \rho>\hat{\rho}(\alpha) \text { : } d M / d \rho>\partial N / \partial \rho \\
& \text { 3) when } \rho=\hat{\rho}(\alpha) \text { : } d M / d \rho=\partial N / \partial \rho \text {. }
\end{aligned}
$$

Combining (A9) and (A11) with (A5), we can deduce that $M(\rho)<N(\rho, \alpha)$ for all $\rho \in$ $(1 /(1-\phi), \hat{\rho}(\alpha)]$. Furthermore, because of $($ A10) and (A6), we can observe that: $\exists \bar{\rho}>\hat{\rho}(\alpha)$, such that $M(\bar{\rho})=N(\bar{\rho}, \alpha)$, and $M(\rho)>N(\rho, \alpha)$ for all $\rho>\bar{\rho}$, while $M(\rho)<N(\rho, \alpha)$ for all $\rho<\bar{\rho}$. Using again (A4), we can observe that $\bar{\rho}$ must solve:

$$
\eta \frac{1-\phi}{\phi} \frac{(1-\phi) \bar{\rho}-1}{(1-\phi) \bar{\rho}}=1-\left[\frac{1}{(1-\phi) \bar{\rho}}\right]^{\frac{1}{1-\alpha}}
$$

from where it follows that $\bar{\rho}=\bar{\rho}(\alpha)$. This completes the proof that $\exists \bar{\rho}(\alpha)>1 /(1-\phi)$, such that for all $\rho>\bar{\rho}(\alpha)$ there exists another locally stable stationary point at $\omega=(1-\phi) \rho$.

Finally, totally differentiating (A12), we get:

$$
\frac{d \bar{\rho}}{d \alpha}=\frac{\phi \bar{\rho}^{2}(1-\alpha)^{-2}[(1-\phi) \bar{\rho}]^{-\frac{1}{1-\alpha}} \ln [(1-\phi) \bar{\rho}]}{\eta-\phi \bar{\rho}^{2}[(1-\alpha) \bar{\rho}]^{-1}[(1-\phi) \bar{\rho}]^{-\frac{1}{1-\alpha}}}
$$

Given that at $\rho=\bar{\rho}, d M / d \rho>\partial N / \partial \rho$, the denominator in the right-hand side of (A13) must thus be positive. Furthermore, the numerator in the right-hand side of (A13) is also positive, because $\bar{\rho}>1 /(1-\phi)$. As a result, it follows that $d \bar{\rho} / d \alpha>0$. \|

Part $(i i)$. Note first that $\partial N / \partial \alpha>0$. As a result, if (A4) does not hold for $\alpha \rightarrow 0$, it will not hold for any $\alpha \in(0,1)$ either. Taking the limit on (A4) as $\alpha \rightarrow 0$ :

$$
\text { if } \alpha \rightarrow 0: \hat{\omega}<(1-\phi) \rho \Leftrightarrow \frac{\eta(1-\phi)}{\phi}\left[1-\frac{1}{(1-\phi) \rho}\right]>1-\frac{1}{(1-\phi) \rho}
$$


Therefore, if $\phi /[\eta(1-\phi)] \geq 1$, (A14) implies that $\hat{\omega} \geq(1-\phi) \rho$ when $\alpha \rightarrow 0$, and thus the only stable stationary point is $\omega=1$. Lastly, the proof that if $\phi /[\eta(1-\phi)] \in(1-\alpha, 1)$ holds, but $\rho \leq \bar{\rho}(\alpha)$, the only stable stationary equilibrium is $\omega=1$, follows directly from the proof of Part $(i) . \|$

Part (iii). If $\phi /[\eta(1-\phi)] \leq 1-\alpha$, then: $\left.\frac{d \omega_{t}}{d \omega_{t-1}}\right|_{\omega_{t-1}=1} \geq 1$. As a consequence, the fixed point $\omega=1$ is locally unstable. Moreover, because $\Psi\left(\omega_{t}, \omega_{t-1}\right)=0$ yields an increasing an convex function in $\omega_{t-1}$, it follows that:

$$
\frac{d \omega_{t}}{d \omega_{t-1}}>1, \quad \forall \omega_{t-1} \in[1, \bar{\omega}]
$$

Given (A15), it then follows that $\omega_{t}>\omega_{t-1}$ for all $\omega_{t-1} \in(1, \bar{\omega}]$. Therefore, $\hat{\omega}<\bar{\omega}$, and thus $\omega=(1-\phi) \rho$ is the unique stable fixed point of $(12)$.

\section{Appendix B: Alternative Specification of Preferences}

Drop now the assumption that individuals need to consume one unit of income while they are young (hence, they will consume the entire $\omega_{t-1}$ in $t$ ). In addition, assume $u_{i, t}=c_{i, t+1}^{1-\sigma} /(1-\sigma)$; that is, utility displays CRRA, where $\sigma>0$ denotes the coefficient of relative risk aversion. From now onwards, restrict the attention to $1<\omega_{t-1}<(1-\phi) \rho$. The optimisation problem for a good type born in $t-1$-analogous to that in (7)-(8)- yields:

$$
l^{*}=\frac{(1-\phi)}{(1-\phi) \rho-\omega_{t}}\left\{\left[\frac{(1-\phi)\left(\rho-\omega_{t}\right)}{\omega_{t} \phi}\right]^{\frac{1}{\sigma}}-1\right\} \omega_{t-1} \equiv \Pi\left(\omega_{t}\right) \omega_{t-1} .
$$

Let $\varepsilon\left(\omega_{t}\right)$ denote the wage-elasticity of labour demand in (A16); that is: $\varepsilon\left(\omega_{t}\right) \equiv-\Pi^{\prime}\left(\omega_{t}\right) \omega_{t} / \Pi\left(\omega_{t}\right)$.

Lemma A.4. (i) $\sigma>1 \Leftrightarrow \varepsilon\left(\omega_{t}\right)<1$, (ii) $\sigma<1 \Leftrightarrow \varepsilon\left(\omega_{t}\right)>1$, (iii) $\sigma=1 \Leftrightarrow \varepsilon\left(\omega_{t}\right)=1$.

Proof. Available upon request.

Since labour supply remains the same, the law of motion can be written as follows: $\omega_{t-1}=\left(1-\omega_{t}^{-\frac{1}{1-\alpha}}\right) / \Pi\left(\omega_{t}\right)$. Thus,

$$
\frac{d \omega_{t}}{d \omega_{t-1}}=\Pi\left(\omega_{t}\right)\left[\frac{1}{1-\alpha} \omega_{t}^{\frac{\alpha-2}{1-\alpha}}-\left(1-\omega_{t}^{-\frac{1}{1-\alpha}}\right) \frac{\Pi^{\prime}\left(\omega_{t}\right)}{\Pi\left(\omega_{t}\right)}\right]^{-1} .
$$

From where we can observe that $d \omega_{t} / d \omega_{t-1}>0$ still holds true under this new setup. Next, 
dividing and multiplying the RHS in (A17) by $\omega_{t}$ yields:

$$
\frac{d \omega_{t}}{d \omega_{t-1}}=\frac{\Pi\left(\omega_{t}\right) \omega_{t}}{\frac{1}{1-\alpha} \omega_{t}^{-\frac{1}{1-\alpha}}+\left(1-\omega_{t}^{-\frac{1}{1-\alpha}}\right) \varepsilon\left(\omega_{t}\right)} .
$$

Focus, for the moment, on the case in which $\sigma=1$. Since $\sigma=1$ implies $\varepsilon\left(\omega_{t}\right)=$ 1, which in turn also means that $\Pi\left(\omega_{t}\right) \omega_{t}$ is a constant, we can observe from (A18) that $d^{2} \omega_{t} /\left(d \omega_{t-1}\right)^{2}>0$ still holds true in this alternative setup. ${ }^{18}$ Therefore, dynamics similar to those depicted in Figure 2.(b) and Figure 2.(c) are still possible with logarithmic utility, even if individuals consume all their initial income, $\omega_{t-1}$, when they are old. ${ }^{19}$

However, to obtain dynamics where multiple equilibria coexist for a given set of parameters -like those in Figure 2.(a)-, a slightly stronger condition is required, namely: $\sigma>1$. To see this, notice that a necessary condition for multiple equilibria to coexist is that: $d \omega_{t} / d \omega_{t-1}>1$ when $\omega_{t}=\omega_{t-1}$, at least once. (So that the mapping $\omega_{t}\left(\omega_{t-1}\right)$ crosses the $45^{\circ}$ line at least once from below.) Set thus $\omega_{t-1}=\omega_{t}=\omega$. Then, using the fact that $\varepsilon\left(\omega_{t}\right) \Pi\left(\omega_{t}\right) \equiv-\Pi^{\prime}\left(\omega_{t}\right) \omega_{t}$, we may obtain:

$$
\left.\frac{d \omega_{t}}{d \omega_{t-1}}\right|_{\omega}=\frac{\Pi(\omega)}{\frac{1}{1-\alpha} \omega^{\frac{\alpha-2}{1-\alpha}}+\varepsilon(\omega) \Pi(\omega)}
$$

from where it follows that $\varepsilon(\omega)<1$ is necessary for that derivative to be larger than 1 . To grasp some intuition for this result, suppose we are on the $45^{\circ}$ line, so $\omega_{t-1}=\omega_{t}=\omega$. If $\varepsilon\left(\omega_{t}\right) \geq 1$, an increase in $\omega_{t-1}$ cannot lead to an even larger increase in $\omega_{t}$, since that would actually reduce labour demand in (A16) -leading to a lower $\omega_{t}$, rather than a larger oneIn contrast, when $\varepsilon\left(\omega_{t}\right)<1$, an increase in $\omega_{t-1}$ could lead to an even larger increase in $\omega_{t}$, since in this case the negative effect of the higher wage need not completely revert the positive effect induced by a larger $\omega_{t-1} \cdot{ }^{20}$

\footnotetext{
${ }^{18}$ It must also be quite intuitive to observe that convexity, i.e. $d^{2} \omega_{t} /\left(d \omega_{t-1}\right)^{2}>0$, should be even stronger if $\sigma>1$, since in this case $\varepsilon\left(\omega_{t}\right)<1$ and the numerator in (A18) becomes increasing in $\omega_{t}$.

${ }^{19}$ One difference with respect to the model in the main text is that the poverty trap would have $\omega>1$. However, this is just because $y(1)=1$, and may be easily accommodated with different specifications for the agricultural production function that still exhibit decreasing marginal productivity.

${ }^{20}$ Notice that the wage-elasticity in $(10)$ is strictly smaller than unity. This is owing to the fact that individuals must consume 1 unit of income while they are young.
} 


\section{References}

[1] Acemoglu, D. and Zilibotti, F. (1997), Was Prometheus Unbound by Chance? Risk, Diversification and Growth, Journal of Political Economy 105, 709-751.

[2] Acemoglu, D. and Zilibotti, F. (1999), Information Accumulation in Development, Journal of Economic Growth 4, 5-38.

[3] Aghion, P. and Bolton, P. (1997), A Theory of Trickle-Down Growth and Development, Review of Economic Studies 64, 151-172.

[4] Banerjee, A. (2000), The Two Poverties, Nordic Journal of Political Economy 26, 129-141.

[5] Banerjee, A. and Newman, A. F. (1991), Risk-Bearing and the Theory of Income Distribution, Review of Economic Studies 58, 211-235.

[6] Banerjee, A. and Newman, A. F. (1993), Occupational Choice and the Process of Development, Journal of Political Economy 101, 274-298.

[7] Besley, T. (1995), Nonmarket Institutions for Credit and Risk Sharing in Low-Income Countries, Journal of Economic Perspectives 9, 115-127.

[8] Blake, D. (1996), Efficiency, Risk Aversion and Portfolio Insurance: An analysis of financial asset portfolios held by investors in the United Kingdom, Economic Journal 106, 1175-1119.

[9] Chiappori, P. A. and Paiella, M. (2008), Relative Risk Aversion Is Constant: Evidence from Panel Data, DES (Univ. of Naples) Discussion Papers No. 5/2008.

[10] Evans, D. and Jovanovic, B. (1989), An Estimated Model of Entrepreneurial Choice under Liquidity Constraints. Journal of Political Economy 97, 808-827.

[11] Galor, O. and Zeira, J. (1993), Income Distribution and Macroeconomics. Review of Economic Studies 60, 35-52.

[12] Ghatak, M. and Jiang, N. (2002), A Simple Model of Inequality, Occupational Choice, and Development. Journal of Development Economics 69, 205-226. 
[13] Greenwood, J. and Jovanovic, B. (1990), Financial Development, Growth, and the Distribution of Income. Journal of Political Economy 98, 1076-1107.

[14] Guiso, L., Jappelli, T. and Terlizzese, D. (1996), Income Risk, Borrowing Constraints, and Portfolio Choice. American Economic Review 86, 158-172.

[15] Jaffee, D. and Russell, T. (1976), Imperfect Information, Uncertainty, and Credit Rationing. Quarterly Journal of Economics 90, 651-666.

[16] Jaimovich, E. (2009), Sectoral Differentiation, Allocation of Talent, and Financial Development, manuscript, Collegio Carlo Alberto.

[17] Kimball, M. (1990), Precautionary Saving in the Small and in the Large. Econometrica 58, $53-73$.

[18] Lloyd-Ellis, H. and Bernhardt, D. (2000), Enterprise, Inequality and Economic Development. Review of Economic Studies 67, 147-168.

[19] Leland, H. and Pyle, D. (1977), Informational Asymmetries, Financial Structure, and Financial Intermediation. Journal of Finance 32, 371-387.

[20] Mookherjee, D. and Ray, D. (2002), Contractual Structure and Wealth Accumulation. American Economic Review 92, 818-849.

[21] Morin, R. and Fernandez Suarez, A. (1983), Risk Aversion Revisited, Journal of Finance 38, $1201-1216$.

[22] Myers, S. and Majluf, N. (1984), Corporate Financing and Investment Decisions when Firms Have Information that Investors Do Not Have. Journal of Financial Economics 13, 187-221.

[23] Newman, A. F. (2007), Risk-Bearing and Entrepreneurship. Journal of Economic Theory 137, $11-26$.

[24] Ogaki, M. and Zhang, Q. (2001), Decreasing Relative Risk Aversion and Tests of Risk Sharing. Econometrica 69, 515-526. 
[25] Piketty, T. (1997), The Dynamics of the Wealth Distribution and the Interest Rate with Credit Rationing. Review of Economic Studies 64, 173-189.

[26] Quah, D. (1993), Empirical Cross-Section Dynamics in Economic Growth. European Economic Review 37, 426-434.

[27] Quah, D. (1996), Twin Peaks: Growth and Convergence in Models of Distribution Dynamics. Economic Journal 106, 1045-1055.

[28] Rosenzweig, M and Binswanger, H. (1993), Wealth, Weather Risk and the Composition and Profitability of Agricultural Investments. Economic Journal 103, 56-78.

[29] Rothschild, M. and Stiglitz, J. (1976), Equilibrium in Competitive Insurance Markets: An Essay on the Economics of Imperfect Information. Quarterly Journal of Economics 90, 629649.

[30] Saint-Paul, G. (1992), Technological Choice, Financial Markets and Economic Development. European Economic Review 36, 763-781.

[31] Stiglitz, J. (1990), Peer Monitoring and Credit Markets. World Bank Economic Review 4, $352-366$.

[32] Stiglitz, J. and Weiss, A. (1981), Credit Rationing in Markets with Imperfect Information. American Economic Review 71, 393-410.

[33] Townsend, R. (1994), Risk and Insurance in Village India. Econometrica 62, 539-591.

[34] Udry, C. (1990), Credit Markets in Northern Nigeria: Credit as Insurance in a Rural Economy. World Bank Economic Review 4, 251-269

[35] Udry, C. (1994), Risk and Insurance in a Rural Credit Market: An Empirical Investigation in Northern Nigeria. Review of Economic Studies 61, 495-526. 